\title{
The effect of 3,4- methylenedioxymethamphetamine on expression of neurotrophic factors in hippocampus of male rats
}

\author{
Sara Soleimani Asl ${ }^{1,2}$, Mohamad Bakhtiar Hesam Shariati ${ }^{1}$, Mehdi Medizadeh $^{3}$, Mohammad Ahmadpanah ${ }^{1}$, \\ Maryam Sohrabi ${ }^{2 *}$
}

Received: 7 Dec 2016

Published: 10 Sep 2017

\begin{abstract}
Background: 3,4- methylenedioxymethamphetamine (MDMA) is a chemical derivative of amphetamine that can induce learning and memory impairment. Due to the effect of neurotrophins on memory and learning, the impact of MDMA was evaluated on the brain - derived neurotrophic factor (BDNF), neurotrophin- 4 (NT-4), and tropomyosin- related kinase B (Trk- $\beta$ ) expression in the hippocampus.

Methods: In this study, 20 adult male Wistar rats $(200-250 \mathrm{~g})$ received saline $(1 \mathrm{~mL})$ or $10 \mathrm{mg} / \mathrm{kg}$ of MDMA intraperitoneally as single or multiple injection for 2 consecutive days per week for 2 months. Expression of BDNF, Trk- $\beta$, and NT4 were assessed using Western blotting and RT PCR methods.

Results: Our results revealed that the expression of BDNF, Trk- $\beta$, and NT4 proteins and genes significantly decreased in MDMA groups compared to the sham group $(\mathrm{p}<0.05)$. Furthermore, the acute group showed the lowest expression of these proteins.

Conclusion: The results of the present study suggest that ecstasy administration may downregulate the expression of BDNF, Trk- $\beta$, and NT-4 in hippocampus, which is more extensive in case of acute treatment. It seems that in the chronic group, hippocampus was able to compensate the ecstasy- induced neurotoxicity.
\end{abstract}

Keywords: Ecstasy, BDNF, Trk- $\beta$, NT4

Copyright $₫$ Iran University of Medical Sciences

Cite this article as: Soleimani Asl S, Hesam Shariati MB, Medizadeh M, Ahmadpanah M, Sohrabi M. The effect of 3,4- methylenedioxymethamphetamine on expression of neurotrophic factors in hippocampus of male rats. Med J Islam Repub Iran. 2017 (10 Sep);31:60. https://doi.org/10.14196/mjiri.31.60

\section{Introduction}

According to the United Nation report on drug and crime, amphetamines are the second major class of illicit drugs consumed for recreational purposes worldwide (1). 3, 4-methylenedioxymetamphetamine (MDMA), known as ecstasy, is an amphetamine derivate that causes elevated mood and a heightened sense of empathy. MDMA has been shown to lead to serotonergic, dopaminergic, and noradrenergic neuronal toxicity with more affinity for serotonergic ending. This substance promotes the release and inhibits the reuptake of serotonin (5-HT) from the nerve endings (2). Previous studies have indicated cognition deficiency and memory impairment in humans following the use of MDMA; these problems could remain even after abstinence from the drug $(3,4)$. Several experimental studies on rodents have demonstrated that

Corresponding author: Dr Maryam Sohrabi, sohrabi3@yahoo.com

1. Research Center for Behavioral Disorders and Substance Abuse, Hamadan University of Medical Sciences, Hamadan, Iran.

2. Anatomy Department, School of Medicine, Hamadan University of Medical Sciences, Hamadan, Iran.

3. Cellular \& Molecular Research Center, Faculty of Advanced Technology in Medicine, Department of Anatomical Sciences, Iran University of Medical Sciences, Tehran, Iran.
MDMA- induced neurotoxicity is characterized by cognitive impairment including deficiencies in spatial learning and memory in Morris water maze (5) and also spatial and egocentric learning in Cincinnati water maze (6), associated with serotonergic system dysfunction both in humans and animals $(6,7)$.

The association between serotonergic neurotoxicity with changes in the neurotrophic factors is now well- documented $(8,9)$.

Neurotrophins such as brain- derived neurotrophic factor (BDNF) and neurotrophin 4 are endogenous proteins that are critical for the proliferation, differentiation, and survival of central nervous system during development and neuroplasticity period throughout life ( For review see von Bartheld) (10). BDNF and NT affect neuronal plastic-

$\uparrow$ What is "already known" in this topic:

There is a large body of evidence on a correlation between MDMA toxicity and memory impairment.

$\rightarrow$ What this article adds:

MDMA modulates BDNF, NT4, and Trk- $\beta$ expression in hippocampus of rats that received acute treatment. 
ity and long- term potentiation through binding to the tropomyosin receptor kinase $\beta(\operatorname{Trk} \beta)(10)$.

Neurotrophins may account for some of the amphetamines derivate effects. In methamphetamine - dependent human abusers, plasma BDNF levels remain elevated after 30 or more days of abstinence (11).

Expression of BDNF, NT3, and Trk $\beta$ is also upregulated in the frontal, parietal, piriform, and hippocampus following serotonergic depleting dose of MDMA $(10 \mathrm{mg} / \mathrm{kg}$ $\mathrm{x} 4$ at 2 - hour intervals on a single day) 1, 7, or 24 hours after receiving the last dose (12). However, the chronic effects of MDMA on BDNF, NT4, and $\operatorname{Trk} \beta$ expression have not yet been examined. In the present study, the effect of MDMA weekend regimen (as chronic model) and MDMA acute administration on the expression of BDNF, NT4, and Trk $\beta$ in the hippocampus were investigated.

\section{Methods}

\section{Chemicals}

MDMA was obtained by the Presidency Drug Control Headquarters (Tehran, Iran) and dissolved in $0.9 \%$ saline.

The other chemicals, unless otherwise stated, were purchased from Sigma (St. Louis, MO, USA).

\section{Animal treatment and experimental procedures}

All experimental procedures were performed in accordance with the guidelines of the ethical committee of Hamadan University of Medical Sciences. Adult male Wistar rats, weighing 200-250 g were included in this experimental study and maintained in the colony room at a temperature of $21 \pm 1^{\circ} \mathrm{C}$ on a 12-h light/12-h dark cycle with access to water and food ad libitum. We checked the rectal temperature before starting any treatment and the animals with a body temperature higher than $37.5^{\circ} \mathrm{C}$ were excluded.

The rats were divided into 4 groups ( $n=5$ per group):

Acute group received a single dose of MDMA (10 $\mathrm{mg} / \mathrm{kg}$ ) or saline $(1 \mathrm{~mL})$ intraperitoneally (Shortall et al. 2013), and the chronic group received MDMA (10mg/kg) or saline $(1 \mathrm{~mL})$ intraperitoneally for 2 consecutive days per week for 2 months (Shortall et al. 2013). Rats in acute group were killed 24 hours after the treatment and those in the chronic group were killed after one week by decapitation. The hippocampi were removed, immediately frozen in liquid $\mathrm{N} 2$, and maintained at $-80^{\circ} \mathrm{C}$ for further analysis.

\section{Western blot analysis}

The right frozen hippocampi were homogenized with $200 \mu \mathrm{L}$ lysis buffer [Ripa buffer and inhibitor cocktail (Sigma Aldrich, St. Louis, MO, USA), 1:20] for 1 hour and centrifuged at $12000 \mathrm{~g}\left(4^{\circ} \mathrm{C}\right)$ for 20 minutes. Protein concentration was determined with a Bio-Rad assay system (Bio-Rad, San Francisco, CA, USA), and $100 \mathrm{mi}-$ crograms of total protein from each sample were denatured with sample buffer $(6.205 \mathrm{mM}$ tris- $\mathrm{HCl}, 10 \%$ glycerol, $2 \%$ SDS, $0.01 \%$ bromophenol blue and $50 \mathrm{mM} 2-$ $\mathrm{ME})$ at $95^{\circ} \mathrm{C}$ for 5 minutes. The denatured proteins were separated on a SDS page (10\% sodium dodecyl sulphate polyacrylamide gel) and transferred to a nitrocellulose membrane (Amersham Pharmacia Biotech, Piscataway,
NJ, USA). Non- specific bindings were blocked with $5 \%$ nonfat dry milk, and membranes were probed with antiBDNF, -NT4, Trk- $\beta$ (1:500; Santa Cruz, CA, USA), and $\beta$-actin (1:1000; Sigma Aldrich, St. Louis, MO, USA) monoclonal antibodies for 2 hours and secondary antirabbit antibodies (1:5000; Santa Cruz, CA, USA) conjugated to alkaline phosphatase (for Trk- $\beta$ ) or horseradish peroxidase (for BDNF and NT-4) for 1 hour. Bands were detected using 5-bromo-4-chloro-3-indolyl phosphate in the presence of nitroblue tetrazolium (Abcam, Cambridge, UK) or ECL kit (Abcam, Cambridge, UK) as a chemiluminescent substrate. Band densities were measured by an image analysis system (UVIdoc, Houston, TX, USA).

\section{Reverse transcription $P C R$}

To achieve total RNA, the left frozen hippocampi were homogenized in $1000 \mu \mathrm{L} \mathrm{RNA}^{\mathrm{TM}}$ (Cinnagen, Tehran, Iran). After adding ice cold chloroform, homogenates were centrifuged $\left(12000 \mathrm{~g}\right.$ for $20 \mathrm{~min}$ at $4^{\circ} \mathrm{C}$ ) and supernatant was precipitated with isopropanol and washed with $75 \%$ ethanol. The RNA was converted to cDNA using a cDNA synthesis kit (Qiagen, Hilden, Germany), following the protocol outlined by the manufacturer. RT- PCR reactions were performed using a PCR Master Kit (Cinnagen, Tehran, Iran) and the following primers:

bdnf (forward :ggtcacagtcctggagaaag and reverse: gtctatccttatgaaccgec)

trkb (forward: aagttctaggtgtctgtgtg and reverse: ttctctcctaccaagcagttc)

nt-4 (forward: ctcctgagtgggacctcttg and reverse: cegecggtcggtcaccagc)

$\beta$-actin (forwad: tgtgatggtgggaatgggtcag and reverse: $\mathrm{ttt}-$ gatgtcacgcacgatttc)

PCR reactions were performed with initial denaturation at $95^{\circ} \mathrm{C}$ for 3 minutes, followed by 33 cycles at $95^{\circ} \mathrm{C}$ for 30 seconds, $56^{\circ} \mathrm{C}$ ( for bdnf and trk- $\beta$ ) and $61^{\circ} \mathrm{C}$ ( for nt-4) for 40 seconds and $72^{\circ} \mathrm{C}$ for 40 seconds, with a final elongation time at $72^{\circ} \mathrm{C}$ for 5 minutes.

The same annealing temperature was used for $\beta$-actin. The products were electrophoresed in 1.5\% agarose gel at 100 volts. Semi-quantitative analysis was assessed by a digital imaging system (UVIdoc, Houston, TX, USA).

\section{Statistical analysis}

All data were presented as mean \pm S.E.M and analyzed using SPSS Version 16 software. The one-way analysis of variance (ANOVA) and Tukey multiple comparison tests were used to analyze the significant difference between the groups. Acceptable significance level was set at $p \leq 0.05$.

\section{Results}

As there was no difference between acute and chronic sham saline groups, herein only 1 sham group was reported.

Figure 1 demonstrates the effect of MDMA on BDNF expression both in Western blot and RT-PCR. Different regimen of MDMA caused the downregulation of the bdnf gene, which was statistically significant for both groups compared with the sham group $(\mathrm{p}<0.01$, Fig. 1A). Further analysis revealed increased bdnf expression in the chronic 
group compared to the acute group, but this increase was not statistically significant. Densitometry from the membrane showed a less expression of the BDNF protein in the MDMA groups compared to saline group, which was statistically significant in case of acute group ( $p<0.05$, Fig. 1B). There was an insignificant difference between the acute and chronic groups such that the acute group expressed less BDNF. As displayed in Fig. 2A, trk- $\beta$ was expressed more in the sham group, and there was a significant difference between the sham and acute groups $(p<0.05)$. Rats that received chronic treatment showed an increase in trk- $\beta$ expression, but the difference was not statistically significant. Western blot analysis revealed more expression of the Trk- $\beta$ protein in the saline group compared to MDMA groups $(\mathrm{p}<0.001$ and $\mathrm{p}<0.05$ for acute and chronic groups, respectively, Fig. 2B). Furthermore, a significant difference was found between the acute and chronic groups, showing a lower Trk- $\beta$ expression in the acute group $(\mathrm{p}<0.01)$.

Quantification of nt 4 expression revealed a significant difference between the saline and MDMA groups $(p<0.05$, Fig. 3A). Moreover, MDMA administration attenuated nt4 expression related to the saline-treated group. Nt4 expression was lower in the acute group compared to the chronic group, but the difference was not significant.

In accordance with nt4 mRNA results, NT4 protein expression decreased in the MDMA- treated groups compared to saline group ( $\mathrm{p}<0.05$, Fig. B). No significant difference was obtained between the acute and chronic groups.
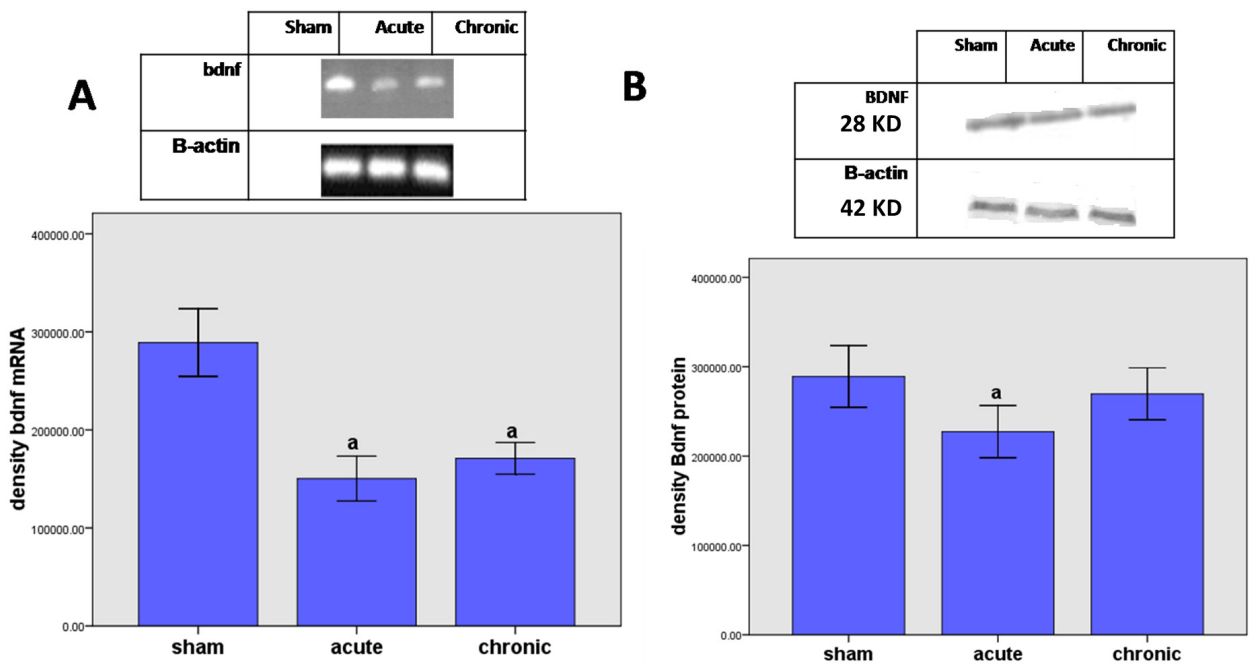

Fig. 1. Mean \pm S.E.M. of bdnf mRNA (A) and Protein (B) Concentrations in the Hippocampus (a $p<0.05$ vs. the Sham Group)
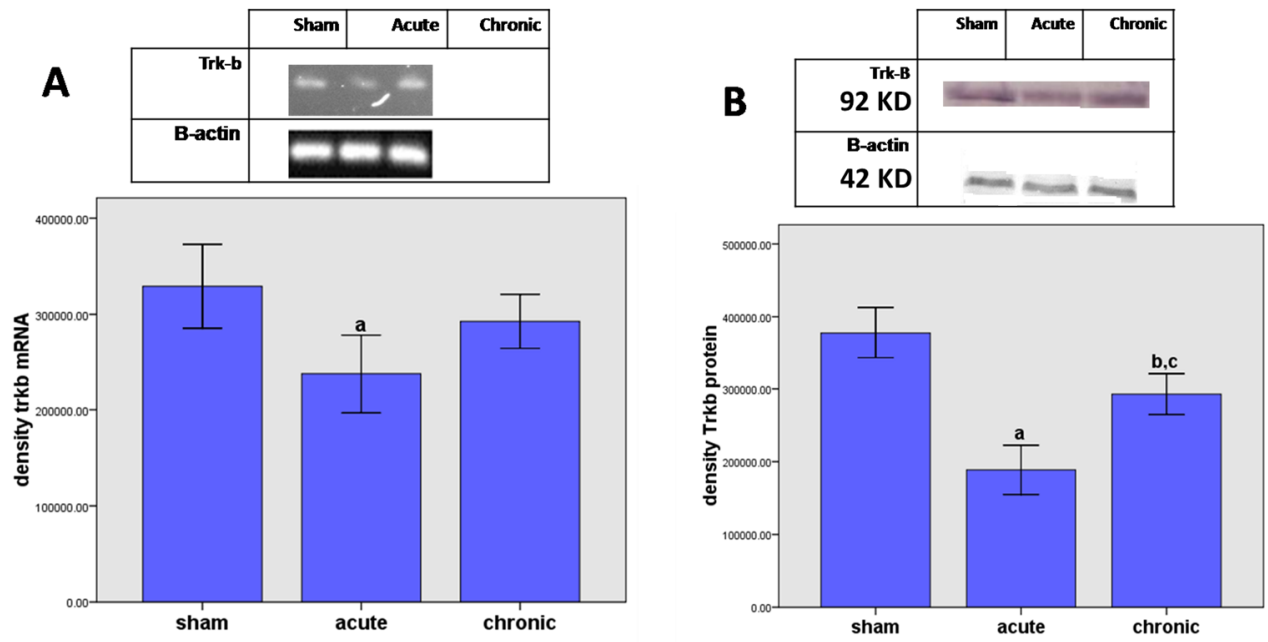

Fig. 2. Mean \pm S.E.M. of trk- $\beta$ mRNA (a $\mathrm{p}<0.05$ vs. the Sham Group, A) and Protein (a $\mathrm{p}<0.001$ and $\mathrm{b} \mathrm{p}<0.05 \mathrm{vs}$. the Sham Group, $\mathrm{c} p<0.01$ vs. Acute Group, B) Concentrations in the Hippocampus 

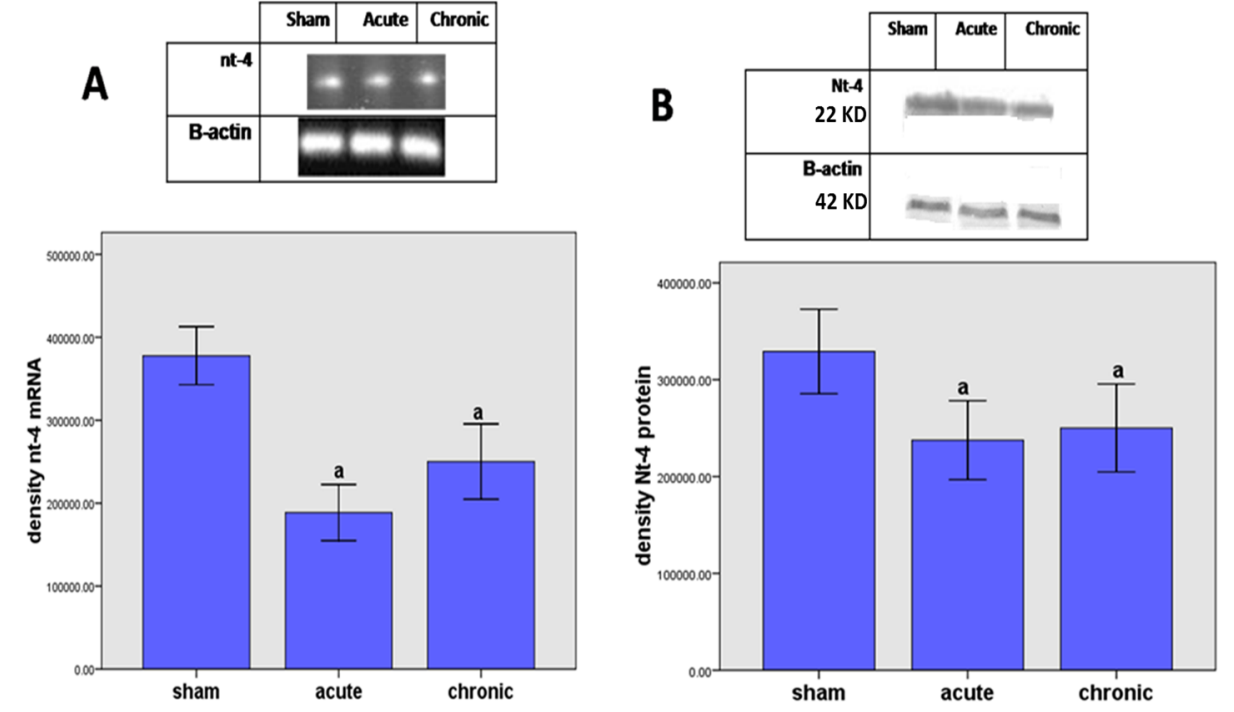

Fig. 3. Mean \pm S.E.M. of nt-4 mRNA (A) and Protein (B) Concentrations in the Hippocampus (a p $<0.05$ vs. the Sham Group)

\section{Discussion}

The present study demonstrated neurotrophins toxicity following MDMA treatment. First, we observed that MDMA treatment caused a reduction in BDNF, Trk- $\beta$, and NT4 expression in the rat hippocampus. Secondly, the rats that received acute treatment showed more reduction compared to the rats that received chronic treatment.

Consistent with our results, Braun et al. demonstrated that administration of methamphetamine as another derivative of amphetamine affects BDNF and $\operatorname{Trk} \beta$ expression and increases BDNF mRNA expression in the hippocampus CA1, prefrontal cortex (PFC), and locus coeruleus. Moreover, in their study, $\operatorname{Trk} \beta$ mRNA expression was modified in the hippocampus, PFC, and striatum (13).

Several studies have demonstrated that MDMA administration can modulate BDNF, however, less is known about the changes in the NT- 4 and Trk- $\beta$ expression. Schaaf et al. found that BDNF expression reduces after corticosterone administration in the hippocampus (14). Neurotrophins and their receptors modulation were obtained in several brain regions after MDMA treatment. It has been reported that neurotoxic agents such as chronic stress decrease BDNF level, but they increase NT-3 levels $(15,16)$.

Hemmerle et al. reported that BDNF mRNA expression was elevated in both frontal and parietal cortices following MDMA treatment at 1- and 7- hour time points (Hemmerle et al. 2012). About hippocampus, the CA1 region remained unchanged for 1 and 7 hours, but was significantly elevated after 24 hours. In contrast to the increase in BDNF expression in the cortical and CA1 regions after 24 hours, MDMA treatment caused a reduction in BDNF levels in the CA3 region at 1 -and 7-hour intervals (12).

These results are inconsistent with those of the present study which revealed that MDMA administration reduces neurotrophins in hippocampus. However, the difference could be due to the fact that in the current study, the examination of MDMA neurotoxicity was performed at time points different from those of Hammerle et al. study. Moreover, the results of the present study showed neurotrophins expression in the entire hippocampus, while Hammerle et al. used in situ hybridization and assessed different regions of hippocampus. Martinez- Turrillas et al. observed an increase in bdnf mRNA expression in the frontal cortex 24 and 48 hours after a single dose of MDMA and a decrease in hippocampus 24 hours, 48 hours, and 7 days following MDMA administration (17), which is in line with the results of the present study. They suggested that neurotrophins were differentially regulated in several regions of the brain. In the present study, an increased expression of BDNF, NT- 4 , and Trk- $\beta$ was observed in the chronic group compared to the acute group. Martinez et al. also reported that BDNF expression increases 7 days after MDMA administration compared to 24 and 48 hours after treatment (17).

The mechanism by which BDNF, NT4, and their receptor expression decrease after MDMA treatment is not yet fully understood. Several lines of evidence have shown that MDMA treatment leads to neuronal degeneration and cell death in hippocampus $(18,19)$. Previous studies have shown that MDMA caused an increase in dead cells but a decrease in neuronal density in the CA1 hippocampus (18). It seems that reduced neurotrophins expression in the hippocampus is the result of neuronal loss. Moreover, it is clear that serotonergic nerve cells project to the hippocampus and that MDMA administration results in serotonin depletion in this area (20). Serotonin alteration in hippocampus is likely to play a role in the changes of neurotrophin expression. Neurotrophins and serotonin are involved in dendritic growth and synaptic plasticity that improve cognition, learning, and memory $(21,22)$. From another aspect, there is an association between corticosterone and neurotrophin expression. It has been revealed that corti- 
costerone regulates the expression of BDNF and Trk- $\beta$ RNA in rat hippocampus and that they are downregulated following corticosterone administration $(15,16,23)$. It seems unlikely that a decrease in BDNF, NT4, and Trk- $\beta$ expression 24 hours after MDMA administration would be the result of cell loss and serotonin depletion; however, it may be tied to the increase in corticosterone following MDMA administration.

\section{Conclusion}

MDMA modulates BDNF, NT4, and Trk- $\beta$ expression in hippocampus. Moreover, the rats that received acute treatment expressed lower amount of neurotrophins compared to the rats receiving chronic treatment. Therefore, it seems that the brain has no opportunity to improve the MDMAinduced toxicity in the acute administration.

\section{Acknowledgments}

The data used in this study were extracted from MSc thesis of M.H. Bakhtiar Shariati. This project was financially supported by Hamadan University of Medical Sciences (No.9206262025).

\section{Conflict of Interests}

The authors declare that they have no competing interests.

\section{References}

1. Drugs UNOo, Crime. World drug report 2010: United Nations Publications; 2010.

2. Simantov R, Tauber M. The abused drug MDMA (Ecstasy) induces programmed death of human serotonergic cells. The FASEB Journal. 1997;11(2):141-6.

3. Bolla KI, McCann UD, Ricaurte GA. Memory impairment in abstinent MDMA (" Ecstasy") users. Neurology. 1998;51(6):1532-7.

4. Zakzanis KK, Young DA. Memory impairment in abstinent MDMA ("ecstasy") users: a longitudinal investigation. Neurology. 2001; 56(7):966-9.

5. Shariati MBH, Sohrabi M, Shahidi S, Nikkhah A, Mirzaei F, Medizadeh $\mathrm{M}$, et al. Acute effects of ecstasy on memory are more extensive than chronic effects. Basic and clinical neuroscience. 2014;5(3):225.

6. Sprague JE, Preston AS, Leifheit M, Woodside B. Hippocampal serotonergic damage induced by MDMA (ecstasy): effects on spatial learning. Physiology \& Behavior. 2003;79(2):281-7.

7. Verkes RJ, Gijsman HJ, Pieters MS, Schoemaker RC, de Visser S, Kuijpers M, et al. Cognitive performance and serotonergic function in users of ecstasy. Psychopharmacology. 2001;153(2):196-202.

8. Grider M, Mamounas L, Le W, Shine H. In situ expression of brainderived neurotrophic factor or neurotrophin3 promotes sprouting of cortical serotonergic axons following a neurotoxic lesion. J Neuroscience Res. 2005;82(3):404-12.

9. Madhav T, Pei Q, Zetterström T. Serotonergic cells of the rat raphe nuclei express mRNA of tyrosine kinase B (trkB), the high-affinity receptor for brain derived neurotrophic factor (BDNF). Molecul Brain Res. 2001;93(1):56-63.

10. von Bartheld CS. Trafficking of Neurotrophins and Their Receptors and Pathological Significance. Handbook of Neurotoxicity: Springer; 2014. p. 1973-2000.

11. Kim DJ, Roh S, Kim Y, Yoon SJ, Lee HK, Han CS, et al. High concentrations of plasma brain-derived neurotrophic factor in methamphetamine users. Neuroscience Letters. 2005;388(2):112-5.

12. Hemmerle AM, Dickerson JW, Herring NR, Schaefer TL, Vorhees $\mathrm{CV}$, Williams MT, et al. ( \pm ) 3, 4-methylenedioxymethamphetamine ("ecstasy") treatment modulates expression of neurotrophins and their receptors in multiple regions of adult rat brain. J Comparat Neurolog. 2012;520(11):2459-74.
13. Braun AA, Herring NR, Schaefer TL, Hemmerle AM, Dickerson JW, Seroogy KB, et al. Neurotoxic (+)-methamphetamine treatment in rats increases brain-derived neurotrophic factor and tropomyosin receptor kinase $\mathrm{B}$ expression in multiple brain regions. Neuroscience. 2011;184:164-71.

14. Schaaf MJ, de Jong J, de Kloet ER, Vreugdenhil E. Downregulation of BDNF mRNA and protein in the rat hippocampus by corticosterone. Brain Rese. 1998;813(1):112-20.

15. Smith MA, Makino S, Kvetnansky R, Post RM. Stress and glucocorticoids affect the expression of brain-derived neurotrophic factor and neurotrophin-3 mRNAs in the hippocampus. J Neuroscience. 1995;15(3):1768-77.

16. Song L, Che W, Min-Wei W, Murakami Y, Matsumoto K. Impairment of the spatial learning and memory induced by learned helplessness and chronic mild stress. Pharmaco Biochemist Behav. 2006;83(2):186-93.

17. Martínez-Turrillas R, Moyano S, Del Río J, Frechilla D. Differential effects of 3, 4-methylenedioxymethamphetamine (MDMA,"ecstasy") on BDNF mRNA expression in rat frontal cortex and hippocampus. Neuroscience Letters. 2006;402(1):126-30.

18. Soleimani Asl S, Saifi B, Sakhaie A, Zargooshnia S, Mehdizadeh M. Attenuation of ecstasy-induced neurotoxicity by $\mathrm{N}$-acetylcysteine. Metabolic brain disease. 2015;30(1):171-81.

19. Renoir T, Païzanis E, El Yacoubi M, Saurini F, Hanoun N, Melfort M, et al. Differential long-term effects of MDMA on the serotoninergic system and hippocampal cell proliferation in 5-HTT knock-out vs. wildtype mice. International Journal of Neuropsychopharmacology. 2008;11(8):1149-62.

20. Gurtman CG, Morley KC, Li KM, Hunt GE, McGregor IS. Increased anxiety in rats after 3, 4-methylenedioxymethamphetamine: association with serotonin depletion. European journal of pharmacology. 2002;446(1):89-96.

21. Ferreira TA, Iacono LL, Gross CT. Serotonin receptor 1A modulates actin dynamics and restricts dendritic growth in hippocampal neurons. European Journal of Neuroscience. 2010;32(1):18-26.

22. Rauskolb S, Zagrebelsky M, Dreznjak A, Deogracias R, Matsumoto $\mathrm{T}$, Wiese $\mathrm{S}$, et al. Global deprivation of brain-derived neurotrophic factor in the CNS reveals an area-specific requirement for dendritic growth. The Journal of Neuroscience. 2010;30(5):1739-49.

23. Schaaf MJ, Hoetelmans RW, de Kloet ER, Vreugdenhil E. Corticosterone regulates expression of BDNF and trkB but not NT $\square 3$ and trkC mRNA in the rat hippocampus. Journal of neuroscience research. 1997;48(4):334-41. 